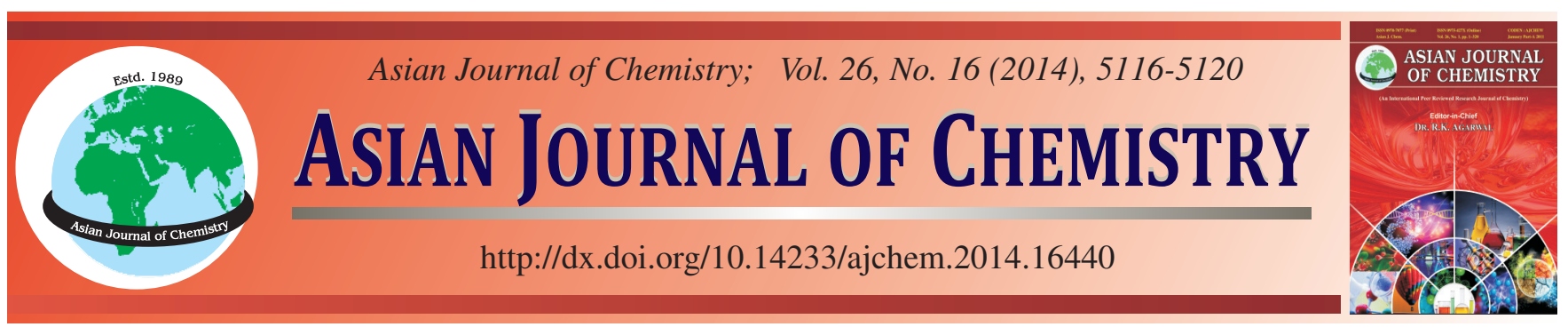

\title{
Investigation of Various Organocatalysts for Improved and Efficient One Pot Synthesis of 2,3-Dihydro-1H-1,5-benzodiazepines Under Solvent-Free Condition
}

\author{
Yuhao ZhaO ${ }^{1, \dagger}$, Shikha Sharma ${ }^{2, \dagger}$, Minghua Huang $^{3}$, Akshdeer Sandhar $^{2}$, Rajesh K. Singh ${ }^{2, *}$ and YanXu Ma ${ }^{3, *}$
}

${ }^{1}$ School of Traditional Chinese Medicine, Capital Medical University, Beijing 100069, P.R. China

${ }^{2}$ Department of Pharmaceutical Chemistry, Shivalik College of Pharmacy (Under Local Govt. Dept. Punjab) Nangal, Distt. Rupnagar- 140126, Punjab, India

${ }^{3}$ Department of Orthopedics, Beijing Traditional Chinese Medicine Hospital, Capital Medical University, Beijing 100010, P.R. China

*Corresponding authors: E-mail: rksingh244@gmail.com; yizhangchaimen@gmail.com

$\dagger$ Authors contributed equally this work

A series of 2,3-dihydro- $1 H$-1,5-benzodiazepines derivatives were synthesized by one-pot three-components condensation reaction of $o$-phenylenediamines with $\alpha, \beta$-unsaturated carbonyl compounds and effect of various Brønsted organo acids as catalyst was studied. Among the various organo acids screened, trifluoroacetic acid is versatile catalyst and the corresponding products were obtained in good to excellent yield (84-94\%) under solvent-free condition.

Keywords: 1,5-Benzodiazepines, Organoacids, Trifluoroacetic acid, One pot, Solvent-free, Green chemistry.

\section{INTRODUCTION}

Benzodiazepines have gained great attention in the area of synthetic medicinal chemistry and form an important component of pharmacologically numerous bioactive compounds which include anticonvulsants, antianxiety, analgesic, sedative, antidepressive, hypnotic, antiinflammatory and muscle relaxant agents ${ }^{1}$. In particular, 1,5-benzodiazepines are useful precursors for the synthesis of fused ring benzodiazepine derivatives such as triazolo, oxadiazolo, oxazino, furano benzodiazepines ${ }^{2}$. More recently their use has been extended to various diseases such as cancer, viral infections (non-nucleoside inhibitors of HIV-1 reverse transcriptase) and cardiovascular diseases ${ }^{3}$.

Literature survey reveals the various catalysts and routes for the synthesis of these compounds by condensation reaction of $o$-phenylenediamines with $\alpha, \beta$-unsaturated carbonyl compounds in the presence of protic organic and inorganic acids catalysts ${ }^{4-12}$. However, majority of them suffer from several limitations such as high temperature, long reaction time, use of expensive reagents, low yields of products, high catalyst loading, corrosive reagents, strongly acidic conditions and further purification of products. Therefore development and introduction of convenient and efficient methods for the preparation of 1,5-benzodiazepines is of practical importance and is still in demand.

In recent years, lot of attention has been directed to green synthesis by organocatalysts owing to their eco-friendliness and commercial availability. The evolution of organocatalysis led to various valuable approaches, such as multicomponent as well as domino and tandem reactions ${ }^{13}$. In continuation with our research for the exploration of various novel catalysts and development of green procedure for the synthesis of various heterocyclic and synthetic intermediates ${ }^{14}$, in this study, we have screened various readily available Brønsted organoacids for their catalytic activity in the synthesis of 1,5-benzodiazepines (Table-1). The synthetic approach is outlined in (Scheme-I). Various aliphatic and aromatic acids have been used to catalyze the synthesis of 1,5-benzodiazepines, out of which trifluoroacetic acid (TFA) came out to be the most effective catalyst under solvent-free condition (Table-1).

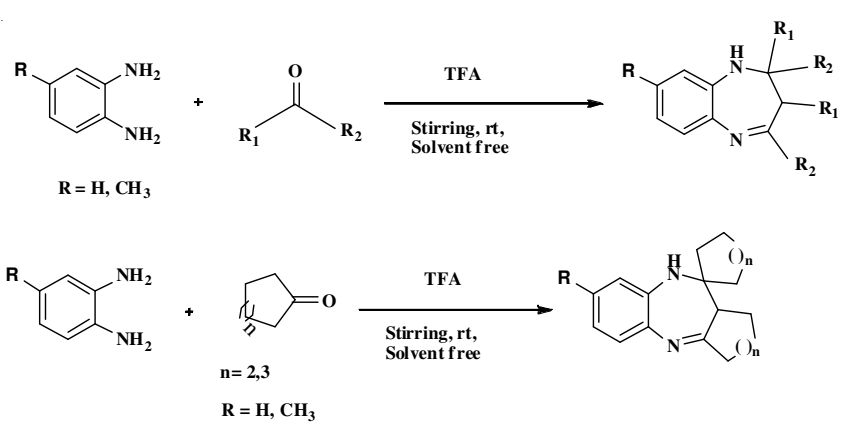

Scheme-I: Chemical reaction for the synthesis of substituted 1,5-benzodiazepines using trifluoroacetic acid (TFA) 


\begin{tabular}{clcc}
\hline \multicolumn{3}{c}{ TABLE-1 } \\
\multicolumn{4}{c}{ REACTION OF $o$-PHENYLENEDIAMINE WITH ACETO- } \\
\multicolumn{2}{c}{ PHENONE PROMOTED BY VARIOUS BRONSTED ACIDS } \\
\hline Entry & Acids & Time $(\mathrm{h})$ & Yield $(\%)$ \\
\hline 1 & Malonic acid & 12 & 80 \\
2 & Maleic acid & 12 & 75 \\
3 & Oxalic acid & 12 & 70 \\
4 & Succinic acid & 12 & 72 \\
5 & Formic acid & 12 & 85 \\
6 & Trichloroacetic acid & 12 & 90 \\
7 & Chloroacetic acid & 12 & 88 \\
8 & Trifluoroacetic acid & 12 & 94 \\
9 & Tartaric acid & 12 & 67 \\
10 & Phthalic acid & 12 & 70 \\
11 & Nicotinic acid & 12 & 72 \\
12 & Cinnamic acid & 12 & 85 \\
13 & Picric acid & 12 & 92 \\
14 & Benzoic acid & 12 & 78 \\
15 & Ascorbic acid & 12 & 74 \\
16 & Palmitic acid & 12 & 50 \\
17 & Molybdic acid & 12 & Very low \\
18 & Glycolic acid & 12 & Very low \\
\hline
\end{tabular}

Recently, trifluoroacetic acid has emerged as a promising catalyst for the synthesis of wide variety of reactions such as Paal-Knorr Furan Synthesis ${ }^{15}$, Meerwein-Ponndorf-VerleyAldol reactions of enolizable aldehydes ${ }^{16}$, Pictet-Spengler reaction ${ }^{17}$, Claisen rearrangement ${ }^{18}$ and cross-coupling reactions ${ }^{19,20}$. Trifluoroacetic acid is the simplest stable perfluorinated carboxylic acid chemical compound, with the formula $\mathrm{CF}_{3} \mathrm{CO}_{2} \mathrm{H}$. It is a strong carboxylic acid due to the influence of the electronegative trifluoro methyl group. Trifluoroacetic acid is almost 100,000-fold more acidic than acetic acid. Using extremely acidic compounds in an organic synthesis allows better manipulations of end products in a reaction. Trifluoroacetic acid is also less oxidizing than sulfuric acid but more readily available in anhydrous from than many other acids. Because of its interesting properties, such as low toxicity, solubility in water and organic solvents and strength, trifluoroacetic acid is considered to be a special reagent for highly sensitive microsequencing of proteins ${ }^{21}$ as well as a special catalyst for promotion of numerous organic reactions $\mathrm{s}^{22}$.

\section{EXPERIMENTAL}

All the chemicals were purchased from commercial suppliers. The melting points were determined on Veegoprogrammable melting point apparatus (microprocessor based) and are uncorrected. ${ }^{1} \mathrm{H}$ NMR spectra were obtained using Brucker AC-400 F, 400 MHZ spectrometer. IR spectra were obtained with Perkin Elmer 882 Spectrum and RXI, FT-IR. Elemental analyses for $\mathrm{C}, \mathrm{H}$ and $\mathrm{N}$ were performed on Thermoflash EA-1112 CHNS-O Analyzer. Reactions were monitored and the homogeneity of the products was checked by TLC. All chemicals were dried and freshly prior to use according to standard procedure.

General procedure for the preparation of 2,3-dihydro$\mathbf{1 H}$-1,5-benzodiazepines: To a solution of $\boldsymbol{o}$-phenylenediamine (10 mmol) in trifluoroacetic acid ( $1 \mathrm{mmol}, 10 \mathrm{~mol} \%)$, various ketones $(22 \mathrm{mmol})$ were added while shaking and kept stirred at room temperature for $12 \mathrm{~h}$. After completion of the reaction [monitored by TLC using $\mathrm{CHCl}_{3}$ and $\mathrm{MeOH}$ (4.5:0.5 mL) as eluent], the reaction mixture was then poured into crushed ice and basified with ammonia solution. The precipitated solid was separated, washed thoroughly with water and dried. The residue was subjected to column chromatography to get the pure 2,3-dihydro-1H-1,5-benzodiazepines (1-9).

2,2,4-Trimethyl-2, 3-dihydro-1H-1,5-benzodiazepine: (Entry 2): IR (KBr, $v_{\max }, \mathrm{cm}^{-1}$ ): 3292 (NH), 2955 (Aromatic $\mathrm{CH}$ ), 1631 (Alkene $\mathrm{C}=\mathrm{C}$ ), 1474 (Aromatic $\mathrm{C}=\mathrm{C}$ ) ${ }^{1} \mathrm{H}$ NMR $\left(\mathrm{CDCl}_{3}\right): \delta 1.3\left(\mathrm{~s}, 6 \mathrm{H},\left(2 \mathrm{xCH}_{3}\right)_{2}\right), \delta 2.2\left(\mathrm{~s}, 2 \mathrm{H},-\mathrm{CH}_{2}\right), \delta 2.4(\mathrm{~s}$, $\left.3 \mathrm{H},-\mathrm{CH}_{3}\right), \delta 6.7-7.2(\mathrm{~m}, 4 \mathrm{H}, \mathrm{ArH})$

Anal. Calcd for $\mathbf{C}_{12} \mathbf{H}_{16} \mathbf{N}_{2}$ : C, 76.55; H, 8.57; N, 14.88; Found: C, 76.51; H, 8.52; N, 14.92

2,3-Dihydro-2-methyl-2,4-diphenyl-1H-1,5-benzodiazepine: (Entry 1): IR (KBr, $\left.v_{\max }, \mathrm{cm}^{-1}\right)$ : 3277 (Sec N-H), 3061 (Aromatic C-H), 2972 (Aliphatic C-H), 1559 (Aromatic C=C).

${ }^{1} \mathbf{H}$ NMR $\left(\mathbf{C D C l}_{3}\right): \delta 1.8\left(\mathrm{~s}, 3 \mathrm{H},-\mathrm{CH}_{3}\right), \delta 3(\mathrm{~d}, 1 \mathrm{H},-\mathrm{CH})$, $\delta 3.2(\mathrm{~d}, 1 \mathrm{H},-\mathrm{CH}), \delta$ 6.8-7.7 ( $\mathrm{m}, 14 \mathrm{H}, \mathrm{ArH})$.

Anal. Calcd for $\mathbf{C}_{22} \mathbf{H}_{20} \mathbf{N}_{2}:$ C, 84.58; H, 6.45; N, 8.97; Found: C, 84.60; H, 6.42; N, 8.94.

2,4-Dimethyl-2-ethyl-2,3-dihydro-1H-1,5-benzodiazepine: (Entry 3): IR ( $\left.\mathrm{KBr}, v_{\max }, \mathrm{cm}^{-1}\right)$ : 3338 (Sec N-H), 3058 (Aromatic C-H), 2968 (Aliphatic C-H), $1639(\mathrm{C}=\mathrm{N}), 1472$ (Aromatic $\mathrm{C}=\mathrm{C}), 1252(\mathrm{C}-\mathrm{N})$

${ }^{1} \mathbf{H}$ NMR $\left(\mathbf{C D C l}_{3}\right): \delta 0.8$ (t, 3H, $\left.-\mathrm{CH}_{3}\right), \delta 1.3$ (brs, $6 \mathrm{H}, 2 \mathrm{x}-$ $\left.\mathrm{CH}_{3}\right), \delta 1.7$ (q, 2H, $-\mathrm{CH}_{2}$ ), $\delta 2.2\left(\mathrm{~m}, 2 \mathrm{H},-\mathrm{CH}_{2}\right), \delta 3.3$ (brs, $1 \mathrm{H}$, $\mathrm{NH}), \delta$ 6.5-7.3 (m, 4H, ArH).

Anal. calcd for $\mathbf{C}_{13} \mathbf{H}_{18} \mathbf{N}_{2}$ : C, 77.18; H, 8.97; N, 13.85; Found: C, 77.25; H, 8.88; N, 14.01

11-Spirocyclocyclohexane-2,3,4,10,11,11a-hexahydro1H-dibenzo[b,e $][1,4]$ diazepine: (Entry 4): $\mathrm{IR}\left(\mathrm{KBr}, v_{\max }\right.$, $\mathrm{cm}^{-1}$ ): 3278 (Sec. NH), 3059 (Aromatic CH), 2858 (Alkane $\mathrm{CH}$ ), 1634 (Imine $\mathrm{C}=\mathrm{N}$ ), 1481 (Aromatic $\mathrm{C}=\mathrm{C}$ ), 751 (ortho substituted oop).

${ }^{1} \mathbf{H}$ NMR $\left(\mathbf{C D C l}_{3}\right): \delta$ 1.2-1.9 $\left(\mathrm{m}, 16 \mathrm{H},-\mathrm{CH}_{2}\right), \delta$ 2.3-2.6 (m, 3H, -CH), $\delta 4.5$ (1H, br, NH), $\delta$ 6.8-7.9 (m, 4H, ArH).

Anal. Calcd for $\mathbf{C}_{18} \mathbf{H}_{24} \mathbf{N}_{2}$ : C, 80.55; H, 9.01; N, 10.44; Found: C, 80.62; H, 9.05; N, 10.54

10-Spirocycloheptan-6,7,8,9,10,10a,11,12-octahydrobenzo $[b]$ cyclohepta[ $e][1,4]$ diazepine: (Entry 5): IR (KBr, $\left.v_{\max }, \mathrm{cm}^{-1}\right): 3266$ (Sec N-H), 2916 (Aromatic C-H), 2972 (Aliphatic C-H), 1633 (Alkene $\mathrm{C}=\mathrm{C}$ ), 1484 (Aromatic $\mathrm{C}=\mathrm{C}$ ).

${ }^{1} \mathbf{H}$ NMR $\left(\mathbf{C D C l}_{3}\right): \delta 1.5-2.4\left(\mathrm{~m}, 20 \mathrm{H},-\mathrm{CH}_{2}\right), \delta 2.4(\mathrm{~s}$, $\mathrm{NH}, 1 \mathrm{H}), \delta 2.6\left(\mathrm{~m}, 2 \mathrm{H},-\mathrm{CH}_{2}\right), \delta 2.8(\mathrm{~m}, 1 \mathrm{H},-\mathrm{CH}), \delta$ 6.6-7.4 (m, 4H, ArH).

Anal. calcd for $\mathbf{C}_{20} \mathbf{H}_{28} \mathbf{N}_{2}$ : C, 81.03; H, 9.52; N, 9.45; Found: C, 81.15; H, 9.56; N, 9.54

2,2,4-Trimethyl-2,3-dihydro-8-methyl-1H-1,5-benzodiazepine:(Entry 6): IR ( $\left.\mathrm{KBr}, \mathrm{v}_{\max }, \mathrm{cm}^{-1}\right): 3454$ (sec. $\left.\mathrm{NH}\right)$, 2924 (Aromatic CH), 2853 (Alkane CH), 1437 (Aromatic $\mathrm{C}=\mathrm{C}), 1236(\mathrm{C}-\mathrm{N}), 946$ (1,2,4-substituted oop)

${ }^{1} \mathbf{H}$ NMR $\left(\mathbf{C D C l}_{3}\right): \delta 1.2\left(\mathrm{~s}, 6 \mathrm{H},-\mathrm{CH}_{3}\right), \delta 1.35(\mathrm{~s}, 3 \mathrm{H}$, $\left.-\mathrm{CH}_{3}\right), \delta 2.3\left(\mathrm{~s}, 3 \mathrm{H},-\mathrm{CH}_{3}\right), \delta 2.3(\mathrm{~d}, 1 \mathrm{H},-\mathrm{CH}), \delta 2.3(\mathrm{~d}, 1 \mathrm{H}$, -CH), $\delta$ 6.5-7.0 (m, 3H, ArH).

Anal. calcd for $\mathbf{C}_{13} \mathbf{H}_{18} \mathbf{N}_{2}$ : C, 77.18; H, 8.97; N, 13.85; Found: C, 77.22; H, 8.91; N, 13.93

2,3-Dihydro-2,8-dimethyl-2,4-diphenyl-1H-1,5benzodiazepine: (Entry 7): IR ( $\left.\mathrm{KBr}, \mathrm{v}_{\max }, \mathrm{cm}^{-1}\right)$ : 3335 (Sec. $\mathrm{NH}$ ), 3057 (Aromatic CH), 2969 (Alkene CH), 2858 (Alkane $\mathrm{CH}$ ), 1612 (Imine $\mathrm{C}=\mathrm{N}$ ), 1493 (Aromatic $\mathrm{C}=\mathrm{C}$ ), $1328(\mathrm{C}-\mathrm{N}$ ), 758 (ortho substituted oop). 
${ }^{1} \mathbf{H}$ NMR $\left(\mathbf{C D C l}_{3}\right): \delta 1.75\left(\mathrm{~s}, 3 \mathrm{H},-\mathrm{CH}_{3}\right), \delta 2.6(\mathrm{~s}, 3 \mathrm{H}$, $\left.-\mathrm{CH}_{3}\right), \delta 2.9(\mathrm{~d}, 1 \mathrm{H},-\mathrm{CH}), \delta 3.1(\mathrm{~d}, 1 \mathrm{H},-\mathrm{CH}), \delta$ 7.2-7.9 (m, $14 \mathrm{H}, \mathrm{ArH}), \delta 2.6$ (br, 1H, NH).

Anal. calcd for $\mathbf{C}_{23} \mathbf{H}_{22} \mathbf{N}_{2}:$ C, 84.63; H, 6.79; N, 8.58; Found: $\mathrm{C}, 84.68 ; \mathrm{H}, 6.84 ; \mathrm{N}, 8.45$

11-Spirocyclocyclohexane-2,3,4,10,11,11a-hexahydro8-methyl-1H-dibenzo[b,e $][1,4]$ diazepine: (Entry 8): IR $\left(\mathrm{KBr}, v_{\max }, \mathrm{cm}^{-1}\right): 3351$ (Sec. NH), 2930 (Alkene CH), 2857 (Alkane $\mathrm{CH}$ ), 1633 (Imine $\mathrm{C}=\mathrm{N}$ ), 1484 (Aromatic $\mathrm{C}=\mathrm{C}$ )

${ }^{1} \mathbf{H}$ NMR $\left(\mathbf{C D C l}_{3}\right): \delta 1.7-2.5\left(\mathrm{~m}, 18 \mathrm{H},-\mathrm{CH}_{2}\right), \delta 3.0(\mathrm{~s}$, $\left.3 \mathrm{H},-\mathrm{CH}_{3}\right), \delta 3(\mathrm{t}, 1 \mathrm{H},-\mathrm{CH}), \delta$ 7.3-7.9 (m, 3H, $\left.\mathrm{ArH}\right)$.

Anal. calcd for $\mathbf{C}_{19} \mathbf{H}_{26} \mathbf{N}_{2}$ : C, 80.80; H, 9.28; N, 9.92; Found: C, 80.86; H, 9.34; N, 9.98.

10-Spirocycloheptan-6,7,8,9,10,10a,11,12-octahydro8-methylbenzo[b]cyclo hepta $[e][1,4]$ diazepine: (Entry 9): IR $\left(\mathrm{KBr}, v_{\max }, \mathrm{cm}^{-1}\right): 3327$ (Sec N-H), 3060 (Aromatic C-H), 2922 (Alkene C-H), 2852 (Aliphatic C-H), 1617 (Alkene $\mathrm{C}=\mathrm{C}), 1492$ (Aromatic $\mathrm{C}=\mathrm{C})$

${ }^{1} \mathrm{H}$ NMR $\left(\mathbf{C D C l}_{3}\right): \delta 1.6\left(\mathrm{~m}, 22 \mathrm{H},-\mathrm{CH}_{2}\right), \delta 2.2(\mathrm{~s}, 3 \mathrm{H}$, $\left.-\mathrm{CH}_{3}\right), \delta 3.1(\mathrm{br}, 1 \mathrm{H},-\mathrm{NH}), \delta 3.1(\mathrm{~s}, 1 \mathrm{H},-\mathrm{CH}), \delta 6.5-7.1(\mathrm{~m}$, $3 \mathrm{H},-\mathrm{CH})$.

Anal. calcd for $\mathbf{C}_{19} \mathbf{H}_{26} \mathbf{N}_{2}:$ C, 81.24; H, 9.74; N, 9.02; Found: C, 81.29; H, 9.79; N, 9.15.

\section{RESULTS AND DISCUSSION}

In search for an efficient catalyst among various catalysts and the best experimental condition, we have studied efficacy of chosen various organocatalysts $(10 \mathrm{~mol} \%)$ by taking $o$ phenylenediamine and acetophenone (1:2.2) as model reaction. We found that trifluoroacetic acid was the most effective catalyst for the synthesis of 1,5-benzodiazepine (Table-1, entry 8) than other acid catalysts which furnished the product in lower yields. Apart from trifluoroacetic acid, chloroacetic acid and trichloroacetic acid has given high yield of $88 \%$ and $90 \%$, respectively which has already been reported ${ }^{14 e}$. Picric acid also found to give excellent yield of $92 \%$ but due to toxicity of picric acid as it was not safe especially in the absence of solvent, this catalyst was not explored further for the synthesis of 1,5-benzodiazepines. It is interesting to mention that using molybdic acid and glycolic acid, the yield of the product was very low (Table -1, entry 17 and 18). At last, we found trifluoroacetic acid as the best catalyst for further synthesis of various substituted 1,5-benzodiazepines. Slight excess of acetophenone was found to be advantageous. Hence, molar ratio of $o$ phenylenediamine to ketone was kept to be $(1: 2.2 \mathrm{mmol})$. Encouraged by these results, a wide variety of ketones were treated with $o$-phenylendiamine using trifluoroacetic acid under the optimized conditions to afford the corresponding 1,5-benzodiazepines (Table-2) in good to excellent yields. Both of the linear and cyclic ketones reacted with the diamines containing electron donating group on aromatic rings, without any significant difference, to give the corresponding 1,5-benzodiazepine derivatives in quantitative yields. No reaction was observed when $o$-phenylenediamine was treated with ketone under similar conditions in the absence of a catalyst.

The proposed mechanism of the reaction (Scheme-II) involves an intramolecular imine enamine cyclization promoted by organoacid. A role of Brønsted organoacids has been proposed to activate the carbonyl group of substituted ketones by activating oxygen atom which ultimately enhances the electrophilicity of the ketones and leads to reduction in reaction time. Amine of $o$-phenylenediamine attacks activated carbonyl group of ketone giving the intermediate diimine A. A 1,3hydrogen shift of the attached methyl group then occurs which require catalytic amount of Brønsted acid as proton source forming isomeric enamine $\mathrm{B}$, which cyclized to afford seven membered benzodiazepine rings.

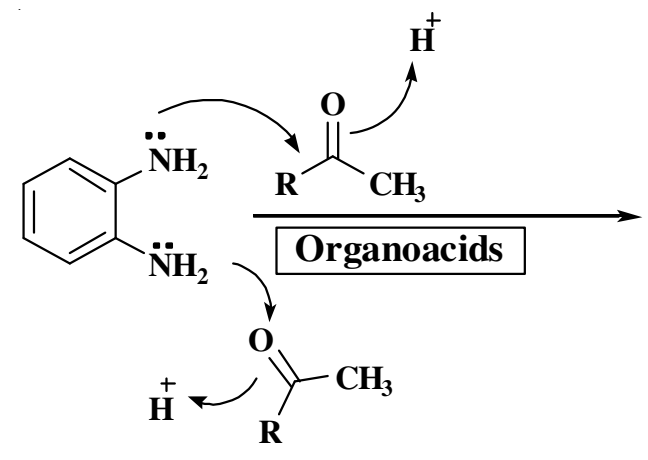

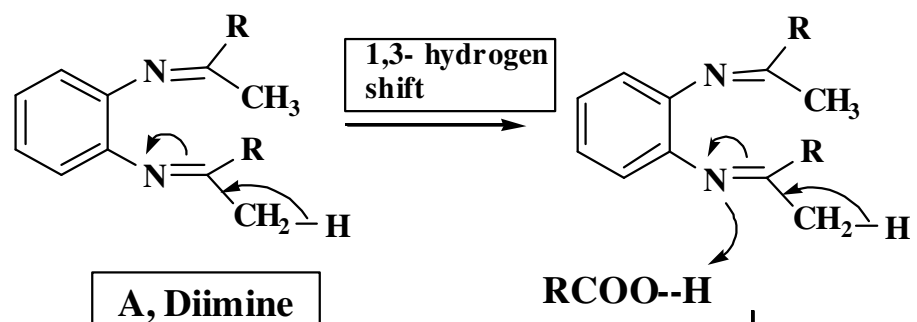<smiles>[R]C1=Nc2ccccc2NC([R])(C)C1</smiles>

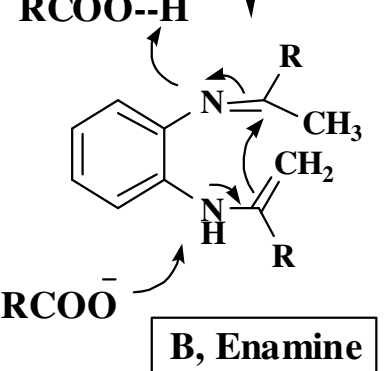




\begin{tabular}{|c|c|c|c|c|c|c|c|}
\hline Entry & Diamine & Ketone & Product & Yield (\%) & Time (h) & m.p. $\left({ }^{\circ} \mathrm{C}\right)$ & m.p. ${ }^{\text {lit. }}\left({ }^{\circ} \mathrm{C}\right)$ \\
\hline 1 & & & & 94 & 12 & $149-150$ & $151-152^{6}$ \\
\hline 2 & & & & 92 & 12 & $138-139$ & $137-139^{6}$ \\
\hline 3 & & & & 87 & 12 & $138-139$ & $137-138^{6}$ \\
\hline 4 & & & & 89 & 12 & $137-138$ & $138-139^{7}$ \\
\hline 5 & & & & 92 & 12 & $133-134$ & $136-137^{7}$ \\
\hline 6 & & & & 90 & 12 & $126-128$ & $127-128^{7}$ \\
\hline 7 & & & & 92 & 12 & $91-92$ & $92-93^{8}$ \\
\hline 8 & & & & 89 & 12 & $140-142$ & $142-143^{8}$ \\
\hline 9 & & & & 85 & 12 & $121-122$ & $124-125^{8}$ \\
\hline
\end{tabular}




\section{Conclusion}

In conclusion, we have found trifluoroacetic acid as the efficient and selective catalyst among various acids screened for the synthesis of 1,5-benzodiazepines under solvent-free conditions. The work out is easy, no solvent is required, reaction condition are mild and yield are excellent. These advantages makes this protocol an attractive and user friendly alternative for the synthesis of 1,5-benzodiazepines using trifluoroacetic acid as catalyst.

\section{ACKNOWLEDGEMENTS}

The authors gratefully acknowledged Dr. D.N. Prasad, Principal and Management Committee, Shivalik College of Pharmacy, Nangal, India for constant encouragement and support. The research is supported by Capital Application Project on Clinical Characteristics of Science and Technology Commission of Beijing Municipality (No. Z111107058811056); Planned Project on Beijing Traditional Chinese Medicine "Inheritance of 3+3 Programme" of Beijing Chinese Medicine Administration Bureau (2011-SZ-C-34). Thanks are also due to SAIF, Panjab University, Chandigarh for cooperation in getting the spectral data.

\section{REFERENCES}

1. L.O. Randall and M. Gordon, Psychopharmacological Agents, Academic Press, New York, vol. 3, pp. 175-281 (1974).

2. H. Schutz, Benzodiazepines, Springer: Heidelberg (1982).

3. R. Varala, R. Enugala and S.R. Adapa, J. Braz. Chem. Soc., 18, 291 (2007).

4. R. Kumar, P. Chaudhary, S. Nimesh, A.K. Verma and R. Chandra, Green Chem., 8, 519 (2006).

5. A. Kamal, N. Shankaraiah, S. Prabhakar, C.R. Reddy, N. Markandeya, K.L. Reddy and V. Devaiah, Bioorg. Med. Chem. Lett., 18, 2434 (2008).
6. D.V. Jarikote, S.A. Siddiqui, R. Rajagopal, T. Daniel, R.J. Lahoti and K.V. Srinivasan, Tetrahedron Lett., 44, 1835 (2003).

7. S. Ahmad and M. Ali, Iran J. Chem. Eng., 26, 93 (2007).

8. B. Das, R. Ramu, B. Ravikanth and V. Saidi Reddy, J. Mol. Catal. Chem., 246, 76 (2006).

9. J.N. Sangshetti, N.D. Kokare and D.B. Shinde, Chin. Chem. Lett., 18, 1305 (2007).

10. R. Kumar and Y.C. Joshi, ARKIVOC, 142 (2007).

11. H. Thakuria, A. Pramanik, B.M. Borah and G. Das, Tetrahedron Lett., 47, 3135 (2006).

12. M. Pozarentzi, J. Stephanidou-Stephanatou and C.A. Tsoleridis, Tetrahedron Lett., 43, 1755 (2002).

13. P.I. Dalko and L. Moisan, Angew. Chem. Int. Ed., 40, 3726 (2001).

14. (a) R. Duvedi and R.K. Singh, Asian J. Chem., 24, 5665 (2012); (b) A. Sandhar, D.N. Prasad and R.K. Singh, Indian J. Heterocycl. Chem., 21, 369 (2012); (c) A. Sandhar, D. Nandan Pra, A. Kapoor and R. K. Singh, Curr. Res. Chem., 4, 68 (2012).; (d) A. Sandhar and R.K. Singh, Asian J. Chem., 24, 5643 (2012); (e) A. Sandhar and R.K. Singh, Chem. Sci. Trans., 2, 176 (2012).; (f) S. Sharma, D.N. Prasad and R.K. Singh, J. Chem. Pharm. Res., 3, 382 (2011); (g) S. Malik, S. Sharma and R.K. Singh, Asian J. Chem., 24, 5669 (2012); (h) P. Kaur, H. Sharma, R. Rana, D.N. Prasad and R.K. Singh, Asian J. Chem., 24, 5649 (2012); (i) P. Kaur and R.K. Singh, Chem. Sci. Trans., 2(S1), 295 (2013).

15. F. Stauffer and R. Neier, Org. Lett., 2, 3535 (2000).

16. A. Seifert, U. Scheffler, M. Markert, R. Mahrwald, Org. Lett., 12, 1660 (2010).

17. A. Yokoyama, T. Ohwada and K. Shudo, J. Org. Chem., 64, 611 (1999).

18. B.H. Bhide, V.D. Akolkar and V.G. Prabhu, ChemInform, 23, 35 (1992).

19. M. Fodili, M. Amari, B. Kolli, A. Robert, M. Baudy-Floch and P. Le Grel, Synthesis, 811 (1999).

20. R. Kaoua, N. Bennamane, S. Bakhta, S. Benadji, C. Rabia and B. Nedjar-Kolli, Molecules, 16, 92 (2011).

21. K.F. Eidman and P.J. Nicholas, in ed.: L. Paquette; TFA: In Encyclopedia of Reagents for Organic Synthesis, Wiley, New York (2004).

22. (a) M.R. Mohammadizadeh, A. Hasaninejad and M. Bahramzadeh, Synth. Commun., 39, 3232 (2009).; (b) S. Fletcher and P.T. Gunning, Tetrahedron Lett., 49, 4817 (2008).; (c) Y.C. Wu, L. Liu, Y.L. Liu, D. Wang and Y.J. Chen, J. Org. Chem., 72, 9383 (2007). 